inactive. The only reasonable correlation of the clubbing was with the growth of the glioma, which initially was too small to be detected but which grew to a large size. It may be concluded that the glioma was in some way the cause of the clubbing, an association that has not been made before. The coexistence of these two features may be important to avoid misdiagnosis in similar cases.

This case also illustrates the difficulty in diagnosing the cause of transient neurological symptoms. ${ }^{4}$ Although the clinical evidence pointed to a transient ischaemic attack, possibly from an endocardial thrombus, the correct diagnosis was a small cerebral tumour probably causing focal epilepsy. ${ }^{5}$

We thank Professor R W Gilliatt for permission to report this case and Dr W G Mair for performing the necropsy.

${ }^{1}$ Mendowitz, M, Medicine (Baltimore), 1942, 21, 269.

2 Lipman, B, and Massie, E, Signs and Symptoms. Philadelphia, Lippincott Press, 1970.

3 Dudley Hart, F, French's Index of Differential Diagnosis. Bristol, Wright, 1973.

Marshall, J, The Management of Cerebrovascular Disease. Oxford, Blackwell, 1976.

${ }^{5}$ Penfield, W, and Erickson, T, Epilepsy and Cerebral Localization. London, Baillière, Tindall, and Cox, 1941.

(Accepted 25 March 1977)

National Hospitals for Nervous Diseases, London WC1 A $M$ WHITELEY, MB, BCHIR, registrar

P R D HUMPHREY, BM, BCH, senior house officer

\section{Brain rhythm that correlates with obesity}

There is a strong correlation between an adult's body weight and usual amount of REM (rapid eye movement) (paradoxical) sleep. ${ }^{1}$ I now report a connection between the degree of obesity and the frequency of an ultradian brain rhythm here measured during sleep but also present by day." Sleep is categorised into two types, REM and NREM (non-rapid eye movement) (or orthodox), which alternate as sleep progresses. A cycle is made up of a period of NREM sleep plus an adjacent period of REM sleep and lasts about 100 minutes.

\section{Subjects, methods, and results}

The sleep of 16 healthy adults ( 10 women and 6 men) aged 52 to 67 years (mean 59 years) was recorded electrophysiologically on six consecutive nights every four weeks during a 16-week period. They were weighed in light clothing on the first and sixth nights. The first night of each six was for adaptation only. Recordings were from $10.15 \mathrm{pm}$ to $7 \mathrm{am}$. The length of each successive sleep cycle in each of the 320 records was computed as the minutes elapsing between the beginning of one period of NREM sleep and the end of the following period of REM sleep. Cycles containing over one minute of wakefulness were excluded. The average length of the first, second, and third cycles in each subject's 20 records was calculated and then the mean taken of the average of the first, second, and third cycles.

The mean of each subject's eight weight measures was calculated and his or her standing height measured. The ideal body weight for each subject's height ${ }^{3}$ was subtracted from their mean measured weight and the deviation expressed as a percentage of the ideal body weight. The percentage deviation from ideal body weight was significantly correlated with the mean NREMREM cycle length $(r=0.563, P<0.03$, two-tailed) (figure), whereas mean body weight was not $(r=0 \cdot 164 ; \mathrm{NS})$. The mean total minutes that subjects slept was also correlated with the percentage deviation from ideal body weight $(r=0.536, P<0.04$, two-tailed), and with the mean sleep cycle length $(r=0.572, P<0.03$, two-tailed $)$.

\section{Comment}

These findings give further evidence for a connection between metabolism and sleep and show an association between a fundamental brain rhythm and the degree by which a person is under or overweight. The correlation with sleep duration confirms the common belief that

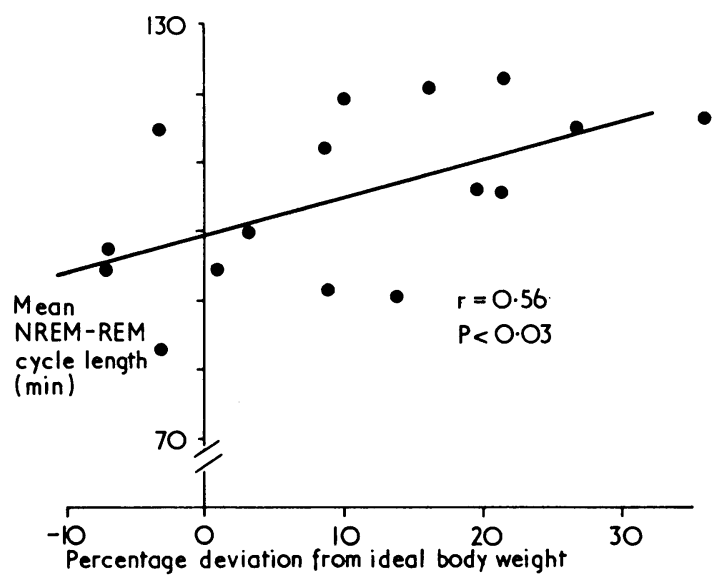

Correlation of percentage deviation from ideal body weight with mean NREM-REM cycle length in 16 adults.

fat people sleep more than thin people, and it agrees with the reported shortening of sleep in obese patients when they reduce weight ${ }^{4}$ and the lengthening of sleep when anorexic patients regain weight. ${ }^{5}$

I thank Dr Ian Oswald and Beecham Products Ltd for their help.

${ }^{1}$ Adam, K, British Medical fournal, 1977, 1, 813.

${ }^{2}$ Kripke, D F, in Advances in Sleep Research, ed E D Weitzman, vol 1. New York, Spectrum Publications, 1974.

${ }^{3}$ Metropolitan Life Insurance Company, Statistical Bulletin, 1960, 41, February, p 6, March p 1.

+ Crisp, A H, et al, Psychotherapy and Psychosomatics, 1973, 22, 159.

5 Lacey, J H, et al, British Medical fournal, 1975, 4, 556.

(Accepted 29 March 1977)

University Department of Psychiatry, Royal Edinburgh Hospital, Edinburgh EH10 5HF

KIRSTINE ADAM, BSC, research associate

\section{Evaluation of digoxin capsules in outpatients}

There are substantial individual differences in the dose of digoxin tablets required to maintain serum concentrations within the therapeutic range. A suitable dose cannot be predicted with confidence even by using nomograms which relate dose to endogenous creatinine clearance. ${ }^{1}$ This may be the result of variable absorption of digoxin from the tablets. ${ }^{2}$ Since absorption of digoxin from capsules (digoxin in a solution of polyethylene glycol encapsulated in soft gelatin) is virtually complete in normal subjects ${ }^{3}$ their use in patients might reduce the amount of trial and error in selecting a non-toxic but adequate dose. The following study tests this hypothesis.

\section{Patients, methods, and results}

Twenty outpatients ( 9 men and 11 women, aged 46 to 75 years, weighing 42 to $85 \mathrm{~kg}$, and with a creatinine clearance of 37 to $120 \mathrm{ml} / \mathrm{min}$ ) on maintenance therapy consented to participate. The patients were randomly allocated to receive for a period of four weeks either digoxin tablets (Lanoxin) $(0.125,0.1875,0.25,0.375$, or $0.5 \mathrm{mg})$ or digoxin capsules $(0.1,0.15,0.2$, 0.3 , or $0.4 \mathrm{mg}$ daily) at $10 \mathrm{am}$. The tablet dose was equal to the total previously received in a day. The capsule dose was 80 "\% of the tablet dose. The dissolution rate of the tablets was greater than $90 \%$, in one hour. At the end of the four-week period the patients crossed over to the alternative treatment. Patient compliance was encouraged by the use of calendar packs and "pill" counting.

During the fourth week on each formulation the following investigations 